Sādhanā Vol. 39, Part 4, August 2014, pp. 859-877. (C) Indian Academy of Sciences

\title{
Design and implementation of PV-based three-phase four-wire series hybrid active power filter for power quality improvement
}

\author{
M VIJAYAKUMAR $^{1, *}$ and S VIJAYAN ${ }^{2}$ \\ ${ }^{1}$ Department of Electrical and Electronics Engineering, KSR College \\ of Engineering, Tiruchengode 637 215, India \\ ${ }^{2}$ Surya Engineering College, Erode 638 107, India \\ e-mail: vijaymettur@yahoo.co.in
}

MS received 17 February 2013; revised 9 October 2013; accepted 23 February 2014

\begin{abstract}
This paper proposes a Photovoltaic (PV)-based three-phase four-wire Series Hybrid Active Power Filter (SHAPF), it comprises of a Series Active Power Filter (SAPF) and an LC shunt passive filter. The proposed system eliminates both the current and voltage harmonics and compensates reactive power, neutral current and voltage interruption. A SAPF demands a source of energy for compensating the voltage sag/swell. This system found a new topology for SHAPF which utilizes the PV with DC-DC boost converter as a source of DC power for the series active filter. The compensation current reference evaluation is based on the twin formulation of the vectorial theory of electrical power theorem with Fuzzy Logic Controller (FLC). The PV array/battery managed DC-DC boost converter is employed to step up the voltage to meet the DC bus voltage requirement of the three-leg Voltage Source Inverter (VSI). The foremost benefit of the proposed system is that, it will provide uninterrupted compensation for the whole day. This system utilizes the renewable energy; accordingly saves the energy and provides the uninterruptable power supply to critical/sensitive load, through the PV array/battery bank during both day time and night time. An experimental model was established and results were obtained, which indicated the capability of the proposed control scheme.
\end{abstract}

Keywords. Photovoltaic (PV) array; DC-DC boost converter; voltage source inverter (VSI); total harmonic distortion (THD); SHAPF; neutral current compensation.

\section{Introduction}

Power Quality is an important issue; a power system has to manage for providing its consumers a reliable and at an economical price. Three-phase four-wire $(3 \mathrm{P} 4 \mathrm{~W})$ distribution systems have

${ }^{*}$ For correspondence 
been mostly used in commercial and industrial establishments. In the 3P4W distribution systems the neutral current transmits the zero sequence current due to unbalanced loading among the phase conductors. Due to huge extension in the area of power electronics, the majority of the industrial and commercial loads posses nonlinear characteristics, such loads are computers, lighting ballasts, switched mode power supply, motor drive applications, etc. These loads are the major source for introducing harmonics in the supply current as well as unreasonable neutral current.

To enhance the power quality, different solutions have been proposed by many authors (Akagi 1996; Bhattacharya et al 1993; Singh et al 1999; Hamadi et al 2007; Fujita \& Akagi 2007; Jindal et al 2005; Asiminoaei et al 2007; Choi \& Jang 2004; Dugan et al 2002). Many researchers have proven that shunt and series active power filters are significant and flexible substituted to compensate current and voltage-based power quality problems in the power system. The Unified Power Quality Conditoner (UPQC) is the other alternative device used to eliminate both the current and voltage-based power problems, but the implementation of UPQC is a costly solution.

A new approach is introduced to compensate the harmonics and reactive power in $3 \mathrm{P} 4 \mathrm{~W}$ distribution system. It is a combination of a shunt passive filter and a series active power filter with a photovoltaic array connected in the DC link. The description of the compensation principle with the excellent functionality of the proposed system to compensate the harmonics in power systems are experimentally verified and validated. The shunt passive LC power filter is used to eliminate current harmonics in the connected load. This compensation part has some drawbacks, because of which; the shunt passive filter cannot equip the complete solution to harmonic distortion. A combined system of series active power filter with passive filter has been proposed to improve the behaviour of passive filters (Das 2004; Rivas et al 2003). To increase the filtering performance of shunt passive LC power filter, series active filter is controlled in such a way that, it increases the network impedance at the harmonic frequency. In the proposed configuration, a series active power filter is connected in series to the source and shunt passive filter in parallel with the load. The shunt passive filter eliminates the prevalent harmonic currents produced by the load, whereas the series active filter joined in series with the source behaves as a 'harmonic isolator' among the source and the load. It also compensates the reactive power and neutral current and also balances unbalanced loads. The proposed control scheme is based on the instantaneous power theory with the FLC. This FLC is designed to adapt PI controller parameters $\mathrm{K}_{\mathrm{p}}$ and $\mathrm{K}_{\mathrm{i}}$ for controlling the DC link voltage of the series active power filter. The active power filter design comprises of a three-phase PWM (Pulse Width Modulation) voltage source inverter (VSI), which is connected in series with an AC source impedance and load, by way of the three single-phase series transformer.

The foremost objective of this paper is to maintain the DC link voltage of the three-phase VSI to provide uninterrupted compensation. The PV array is used to drive the DC-DC boost converter to step-up the voltage and maintain the DC-link voltage. The PV array is connected to the boost converter in day time for continuous compensation and shares the load to the distribution system. During the night time, the battery acts as a DC source for the boost converter and this power only is used for compensation. When the compensation is not required for the system, the PV array charges the battery. With the use of the pulse width modulation technique the boost converter draws constant power from the DC source. The three-phase VSI utilizing fast switching Insulated Gate Bipolar Transistor (IGBT) with a DC bus capacitor is mainly employed for the required compensation.

This paper presents the topology used and the entire scheme of operation of photovoltaic based three-phase series hybrid active power filter with the proposed control scheme. The proposed system has been implemented in hardware and its results are presented. 


\section{Design of series hybrid active power filter}

The proposed scheme of PV-based series hybrid active power filter shown in figure 1. It comprises of PV connected series active power filter, shunt passive filter and typical voltage and current harmonics type of sources. The series active power filter protects the sensitive load from the fluctuation of the supply voltage and voltage-based distortions. It injects the compensation voltage in series with the supply voltage through the coupling transformer and thus considered as a controlled VSI (Routimo et al 2007; Ojo \& Kshirsagar 2004). The required DC bus voltage for series active power filter is provided from the PV array connected with DC-DC boost converter. The VSI consists of IGBTs, inductors and DC capacitors. The value of the DC bus voltage of VSI based series hybrid filter compensation mainly depends on the instantaneous energy available to the active power filter.

Thus, the DC-link capacitor voltage can be maintained at a reference value. However, when the load condition varies, the real power balance between the source and the load will be disturbed. This real power difference will be compensated by DC-link capacitor, it is maintained by DC-DC boost converter.

The DC bus voltage is calculated as follows (Singh et al 2004):

$$
\mathrm{V}_{\mathrm{dc}}=\frac{2 \sqrt{2} \mathrm{~V}_{\mathrm{LL}}}{\sqrt{3} \mathrm{~m}},
$$

where, $\mathrm{V}_{\mathrm{LL}}$ is the $\mathrm{AC}$ line output voltage, $\mathrm{m}$ is the modulation index and is considered as 1 . Thus $\mathrm{V}_{\mathrm{dc}}$ is obtained as $179.62 \mathrm{~V}$ for $\mathrm{V}_{\mathrm{LL}}$ of $110 \mathrm{~V}$ and it is approximated as $180 \mathrm{~V}$. The DC capacitor is calculated using the expression,

$$
1 / 2 \mathrm{C}_{\mathrm{dc}}\left[\left(\mathrm{V}_{\mathrm{dc}}^{2}\right)-\left(\mathrm{V}_{\mathrm{dc} 1}^{2}\right)\right]=3 \mathrm{~V}(\alpha \mathrm{I}) \mathrm{t}
$$

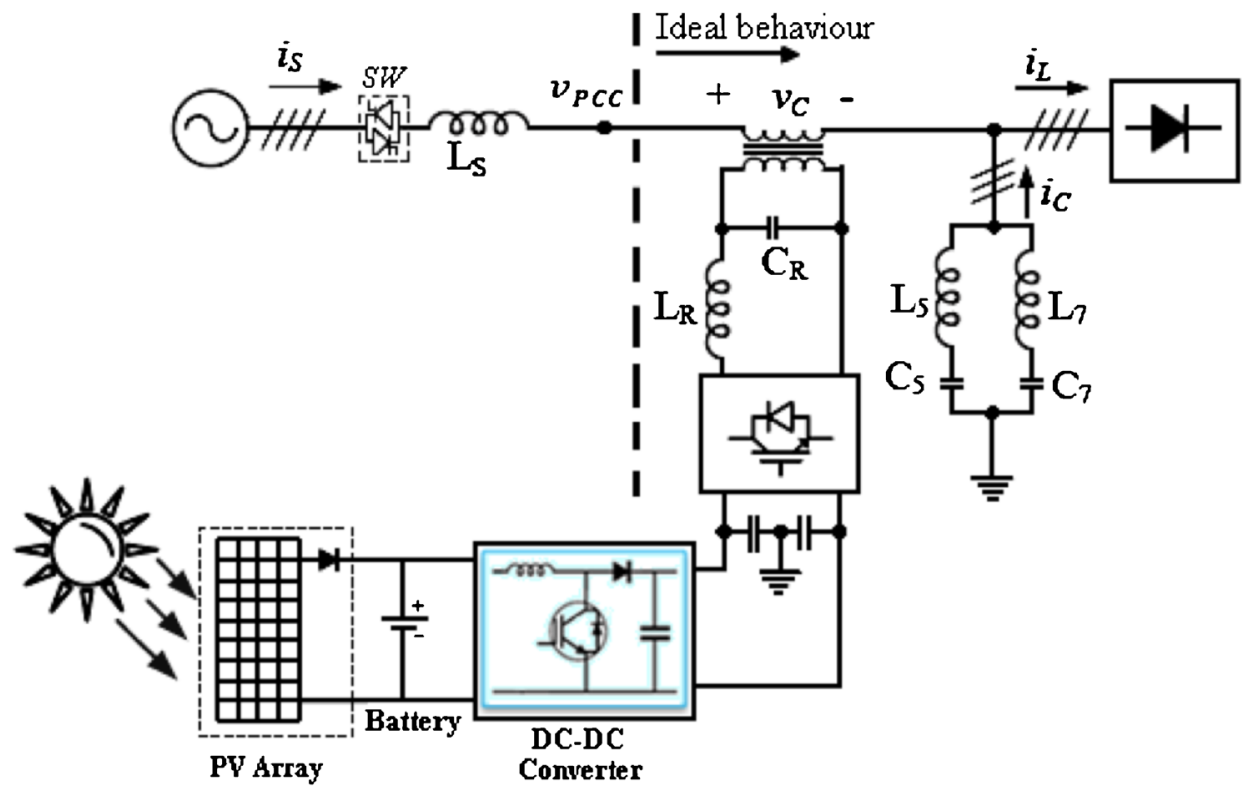

Figure 1. Scheme of PV-based series hybrid active power filter. 
where, $\mathrm{V}_{\mathrm{dc}}$ is the reference DC voltage and $\mathrm{V}_{\mathrm{dc} 1}$ is the minimum voltage level of DC bus, $\alpha$ is the overloading factor taken as 1.2 considering $120-180 \%$ of steady-state current during transient conditions. $\mathrm{V}$ is the phase voltage, $\mathrm{I}$ is the phase current, and $\mathrm{t}$ is the time at which the DC bus voltage is to be recovered. The calculated value of $C_{\mathrm{dc}}$ is $1780 \mu \mathrm{F}$, accordingly $C_{\mathrm{dc}}$ is chosen to be standard available value nearest to calculated value is $2200 \mu \mathrm{F}$.

The design of the inductors is an important matter in the series active filter, because this type of filter must have source current characteristics. The design of inductors affects the DC bus voltage and the THD value of the grid current (Singh et al 2004).

The selection of the AC inductance $\left(\mathrm{L}_{\mathrm{f}}\right)$ of VSI depends on the current ripple $i_{c r, p-p}$, switching frequency $f_{s}$, DC bus voltage $\left(V_{d c}\right)$, and $\mathrm{L}_{\mathrm{f}}$ is expressed as

$$
\mathrm{L}_{\mathrm{f}}=\frac{\sqrt{3} m \mathrm{~V}_{d c}}{12 \alpha f_{s} i_{c r, p-p}},
$$

where $\mathrm{m}$ is the modulation index and $\alpha$ is the overload factor. Considering, $i_{c r, p-p}=5 \%, f_{s}=$ $10 \mathrm{kHz}, \mathrm{m}=1, \mathrm{~V}_{\mathrm{dc}}=180 \mathrm{~V}, \alpha=1.2$, the $\mathrm{L}_{\mathrm{f}}$ value is calculated to be $12.54 \mathrm{mH}$.

The proposed PV-SHAPF operation has been divided into three modes of operation. The modes are; (i) normal mode, (ii) night time (or) unavailability of solar irradiance mode, (iii) voltage interruption mode.

\subsection{Normal mode}

In this mode of operation starts working during the day time or when solar irradiation is available. During this period, the proposed PV-SHAPF is utilized to operate as a harmonic and reactive power compensator. The excessive power of the PV array charges the battery simultaneously.

\subsection{Night time (or) unavailability of solar irradiance mode}

In this mode, the system is utilized only to compensate the voltage and current based distortions and reactive power. The battery connected DC-DC boost converter manages the DC-link to provide continuity of compensation effectively.

\subsection{Voltage interruption mode}

During the voltage interruption period, the series injection transformer of PV-SHAPF is reconfigured into parallel to provide the uninterruptable power supply to critical/sensitive load, through the battery bank during day time and night time. The grid power supply source is disconnected through the Semicondutor Switches $(S W)$, when an occasional power interruption occurs in the incoming power supply.

\section{Control of DC link voltage with boost converter}

The DC-DC boost converter with PV or battery unit is connected in parallel to DC capacitor to maintain the DC link voltage (Kwon et al 2006; Altas \& Sharaf 2007; Jiang et al 2009). The PV/battery unit with DC-DC boost converter arrangement is shown in figure 2 . The DC-DC boost converter comprises of a high speed IGBT switch, inductor, diode and capacitor. The output voltage can be controlled by varying the switching duty cycle (D) of the IGBT $\mathrm{Q}_{1}$. 


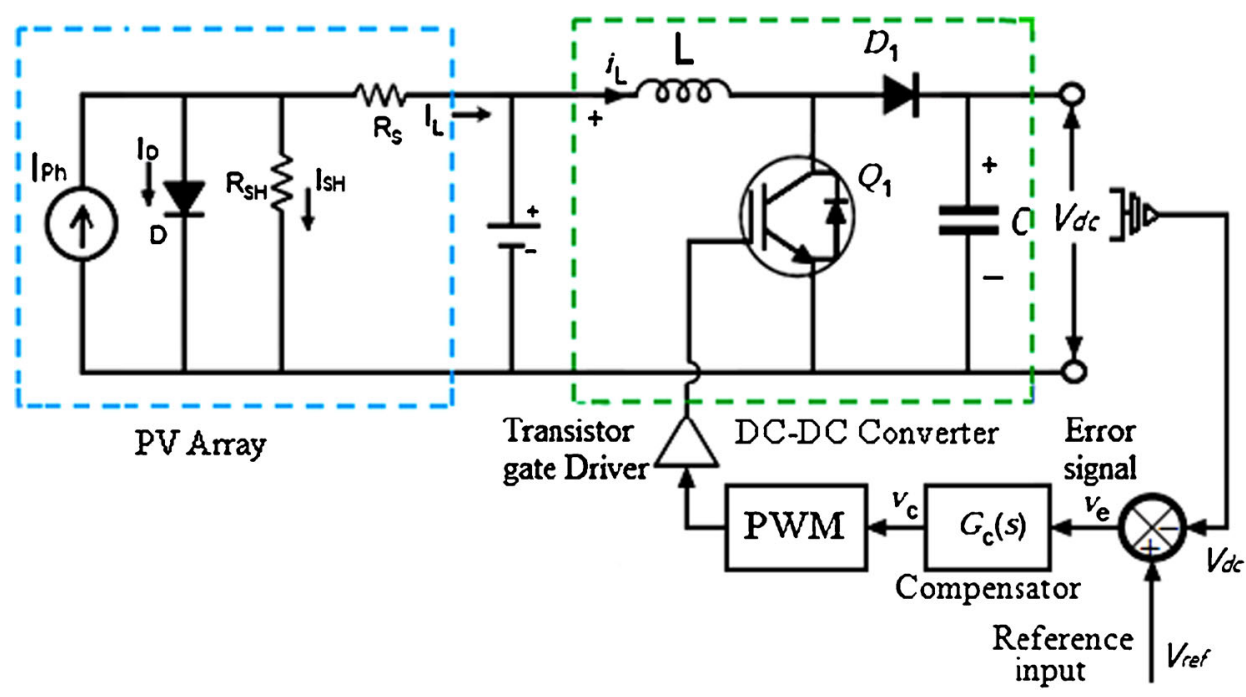

Figure 2. Topology of PV/battery operated DC-DC boost converter.

When the IGBT $\mathrm{Q}_{1}$ is turned on using a PWM generator, current starting flows through $\mathrm{L}$ and IGBT $\mathrm{Q}_{1}$. The energy is stored in the inductor $(\mathrm{L})$, the load current is supplied by the charge in capacitor $\mathrm{C}$.

When the switch IGBT $\mathrm{Q}_{1}$ is turned off, the inductor voltage adds to the source voltage and current due to this boosted voltage now flows from the source through inductor L, diode and the load, which recharges the capacitor $\mathrm{C}$. The Photovoltaic array/battery voltage is fed to the DC$\mathrm{DC}$ boost converter and the output voltage of this boost converter is $180 \mathrm{~V}$ obtained to maintain the DC link voltage of the three-phase VSI.

The selection of the inductance (L) of the boost converter depends on the duty cycle (D), switching frequency $f_{s}$, and $R_{o}$ is expressed as (Mazouz \& Midoun 2011; Rashid 1993). The boost converter inductance given by

$$
(L)=\frac{R_{o}^{*} D(1-D)^{2}}{\left(2 * f_{s}\right)},
$$

where $\mathrm{D}$ is the duty cycle $=1-\mathrm{V}_{\text {in }} / \mathrm{V}_{\text {out }}=1-36 / 180=0.8, \mathrm{f}_{\mathrm{s}}=25 \mathrm{kHz}$ and $\mathrm{R}_{\mathrm{o}}$ is equivalent load resistance $=V_{\mathrm{o}} / \mathrm{I}_{\mathrm{o}} \Omega$, thus inductance $\mathrm{L}$ value obtained as $2.88 \mu \mathrm{H}$ and it is approximated as standard value as $3 \mu \mathrm{H}$.

The capacitor value for the boost converter is calculated using the expression

$$
C=\frac{V_{o}^{*} D}{f_{s} * \Delta V_{o} * R_{o}},
$$

where $\mathrm{V}_{\mathrm{o}}$ is the output voltage of the boost converter, $\Delta \mathrm{V}_{\mathrm{o}}$ is a ripple voltage requirement calculated as $9 \mathrm{~V}$ considering voltage ripple factor $\left(\Delta \mathrm{V}_{\mathrm{o}} / \mathrm{V}_{\mathrm{o}}\right)$ is $5 \%$ thus capacitance value calculated as $142.22 \mu \mathrm{F}$ and is approximated to standard capacitor value is $150 \mu \mathrm{F}$.

Therefore, the output voltage $\mathrm{V}_{\text {out }}$ is higher than the input Voltage $\mathrm{V}_{\text {in }}$ and it turns out that the voltage step-up ratio is equal to:

$$
\frac{\mathrm{V}_{\text {out }}}{\mathrm{V}_{\text {in }}}=\frac{1}{1-\mathrm{D}}
$$


where $\mathrm{V}_{\text {out }}=\mathrm{V}_{\mathrm{dc}}, \mathrm{V}_{\text {in }}=\mathrm{V}$ and

$$
\mathrm{D}=\frac{T_{o n}}{T_{\text {on }}+T_{\text {off }}},
$$

where 1-D is actually the proportion of the switching cycle that $\mathrm{Q}_{1}$ is off, rather than $\mathrm{ON}$. V is the PV or Battery Voltage, D - Duty Cycle, $\mathrm{T}_{\text {on }}$ - On time, $\mathrm{T}_{\text {off }}$ - Off time.

\section{Proposed control strategy}

The power generating system has to handle to provide its consumers a reliable and economical supply with sinusoidal and balanced voltages. Due to this reason, the objective of the compensation based on an ideal reference load, it must be balanced resistive load with linear characteristics. It means that the source currents are in phase with the supply voltage and the system will have unity power factor. The instantaneous power theory with the fuzzy logic controller (FLC) is used to control the VSI (Peng \& Lai 1996; Akagi et al 2007; Herrera \& Salmerón 2007; Salmerón \& Litrán 2010) The Point of Common Coupling (PCC) should follow the linear characteristics, therefore it satisfies the following expression.

$$
\mathrm{V}=R_{e} i,
$$

where $R_{e}$ is the equivalent resistance, $\mathrm{V}$ is the voltage vector at the connection point and $i$-is the load current vector. Voltage and current vectors of three-phase four-wire distribution system can be defined as follows:

$$
v=\left[\begin{array}{lll}
v_{a} & v_{b} & v_{c}
\end{array}\right]^{T} \quad i=\left[i_{a} i_{b} i_{c}\right]^{T} .
$$

Balanced resistive load considered as the ideal reference load, when the system currents are unbalanced and non-sinusoidal. The active power supplied by the source is given by

$$
P_{S}=I_{1}^{+2} R_{e},
$$

where $I_{1}^{+2}$ is the norm of the positive sequence fundamental component of the current vector, whose average is given by

$$
I_{1}^{+2}=\frac{1}{T} \int_{0}^{T}\left(i_{1}^{+T} . i_{1}^{+}\right) d t,
$$

where $i_{1}^{+}$is the positive sequence fundamental component of the instantaneous current vector. Compensator instantaneous power is defined as the difference between the total real instantaneous power required by the load and the instantaneous power supplied by the source. The compensator instantaneous power is

$$
P_{C}=P_{L}-P_{S}
$$

where $P_{L}$ is the total real instantaneous power required by the load, $P s$ is the instantaneous power supplied by the source. The active power exchanged by the compensator is assumed as null, when the average value is calculated. The following expression satisfies this condition:

$$
0=\frac{1}{T} \int P_{L} d t-I_{1}^{+2} R_{e} .
$$


The equivalent resistance is given by

$$
R_{e}=\frac{\frac{1}{T} \int P_{L} d t}{I_{1}^{+2}}=\frac{P_{L}}{I_{1}^{+2}} .
$$

Load average power $\left(\mathrm{P}_{\mathrm{L}}\right)$ is given by

$$
P_{L}=\frac{1}{T} \int P_{L} d t=\frac{1}{T} \int v_{L}^{T} i d t
$$

where $v_{L}^{T}$ is transpose voltage vector at the load side. The objective is that the compensation equipment and load should have an ideal behaviour from the PCC. The voltage at the PCC is given by

$$
v_{P C C}=\frac{P_{L}}{I_{1}^{+2}} i .
$$

The reference signal from the active filter to decide the output voltage of the active filter is given by

$$
v_{C}^{*}=v_{P C C}-v_{L}=\frac{P_{L}}{I_{1}^{+2}} i-v_{L} .
$$

When the active filter supplies the compensation voltage $v_{C}^{*}$, the set load and compensating equipment will behave as a resistor with its equivalent value $R_{e}$.

The reference signal is determined by the proposed controller. The block diagram of the proposed controller is shown in figure 3 .

The controller input signals are voltage and current vectors which are measured from the load and source side, respectively. These current and voltage vectors are multiplied to obtain instantaneous power and load active power is obtained from Low Pass Filter (LPF). In the next stage, this instantaneous power is divided by the norm of the positive sequence fundamental

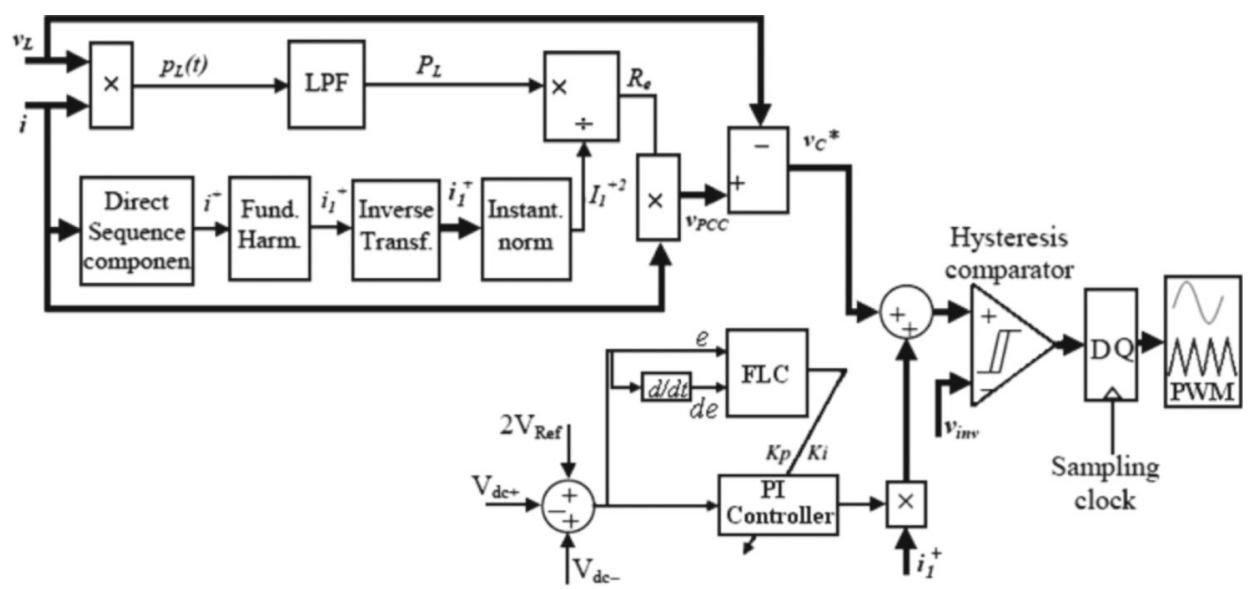

Figure 3. Block diagram of proposed controller. 
component of current vector. The norm of the positive sequence fundamental component of current vector $\left(I_{1}^{+2}\right)$ is derived from the direct sequence component of the current vector using fundamental component calculation block which is shown in figure 4.

By using the LPF block, the norm of the positive sequence fundamental component of current vector is derived as given by

$$
i^{+}=\frac{1}{\sqrt{3}}\left(i_{a}+a i_{b}+a^{2} i_{c}\right)
$$

where, operator ' $a$ ' is defined as $a=\mathrm{e}^{\mathrm{j} 2 \pi / 3}$, by using Fortescue transformation current vector of direct sequence fundamental component is derived and it is calculated by

$$
\vec{i}_{1}^{+}=\left[\begin{array}{lll}
i_{1 a}^{+} & i_{1 b}^{+} & i_{1 c}^{+}
\end{array}\right]^{T}=\left[\begin{array}{lll}
i_{1 a}^{+} & a^{2} i_{1 a}^{+} & a i_{1 a}^{+}
\end{array}\right]^{T},
$$

where $i_{1 a}^{+}, i_{1 b}^{+}$and $i_{1 c}^{+}$are the fundamental components of the direct sequence current vector. To calculate the norm of $i^{+}$vector, it is possible to use the below equation instead of (11), since $\vec{i}_{1}^{+}$ vector is a balanced three phase vector with sinusoidal components.

$$
i_{1}^{+2}=i_{1 a}^{+2}+i_{1 b}^{+2}+i_{1 c}^{+2} .
$$

This modified value of the fundamental components of the direct sequence current vector is implemented in the controller block as instant norm.

In this configuration, two $2200 \mu \mathrm{F}$ capacitors are connected at the three-phase VSI DC-link as split capacitor topology. While maintaining DC-link voltage constant, APF (Active power filter) provides compensated harmonic voltage and reactive power required by the load. In the conventional PWM, the amplitude modulation index is given by

$$
m=\frac{V_{\text {ref }}}{V_{\text {triangle }}},
$$

where $V_{\text {ref }}$ is the amplitude of sinusoidal voltage, and $V_{\text {triangle }}$ is the amplitude of triangular carrier voltage. Therefore, the output voltage of the inverter is

$$
V_{\text {out }}=m^{*} V_{d c}
$$

where $V_{d c}$ is the DC link voltage of APF. DC link capacitor helps in reducing noise. However, in the variable non-linear system, DC link voltage is not constant. Difference between DC link

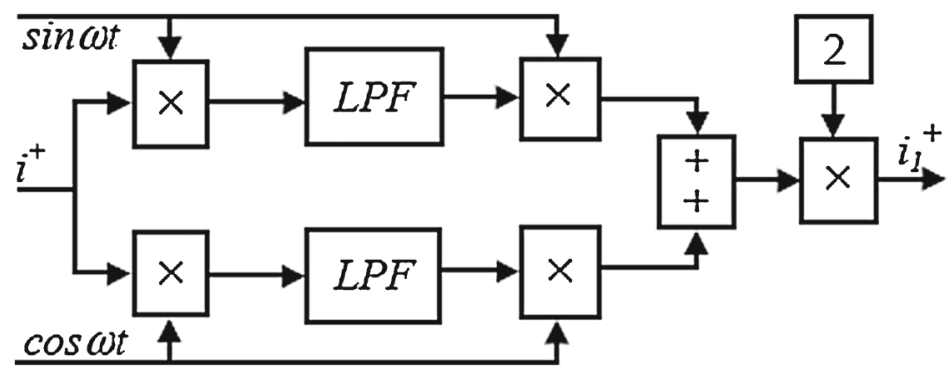

Figure 4. Fundamental component calculation block. 
voltage and reference DC voltage will contain an opposite harmonic component (Vodyakho \& Mi 2009; Rahim et al 2010).

$$
V_{\text {error }}=V_{d c}^{*}-V_{d c}
$$

where $V_{\text {error }}$ is the difference between reference DC link voltage $\left(V_{d c}\right)$ and APF reference DC link voltage $\left(V_{d c}^{*}\right), V_{\text {error }}$ supplies reactive power required by the load and compensating the harmonic voltage. If $V_{\text {error }}$ is required a correction for inverter amplitude modulation index, actual index becomes

$$
m_{\text {actual }}=\frac{V_{\text {error }}{ }^{*} V_{\text {ref }}}{V_{\text {triangle }}} .
$$

Therefore, $V_{\text {out }}$ becomes given by

$$
V_{\text {out }}=m_{\text {actual }}{ }^{*} V_{d c} .
$$

In this proposed control scheme, the fuzzy logic controller (FLC) is designed to adjust the PI controller parameters $K_{p}$ and $K_{i}$, to the purpose of reducing some inbuilt characteristic of the error between the reference and system response (Bose 1999; Jain et al 2002; Saribulut \& Tumay 2011). The main objective of this proposed AFLC (Adaptive fuzzy logic control) structure is to decrease the control scheme complexity without deriving the mathematical modelling and to maintain a high level of the dynamic performances. The fuzzy logic controller inputs are the error $e(n)$ and the error derivative $c e(n)$ and the controller outputs are $\mathrm{K}_{\mathrm{p}}$ and $\mathrm{K}_{\mathrm{i}}$, indicating the weights of the proportional and integral actions of the implemented PI controller. Figure 5 shows the block diagram of the proposed fuzzy logic controller.

The fuzzy sets were defined for both the input and output variables of the proposed fuzzy logic controller. The input variables are labelled as negative $(\mathrm{N})$, zero $(\mathrm{ZE})$ and positive $(\mathrm{P})$ and the outputs are negative big (NB), negative medium (NM), zero (ZE), positive medium (PM) and positive big (PB).

The membership functions of the input and output variables are shown in figure 6 . In this proposed control scheme, the min-max method was used for fuzzification and the defuzzification process was based on the maximum membership principle.

The Rule base stores the linguistic (fuzzy number) control rules required by the rule evaluator (decision making logic). The fuzzy rules used in this control scheme are shown in table 1.

The received normalized input quantities are crisp in nature, hence it needs to convert their corresponding fuzzy variables. After the completion of fuzzification process, the fuzzified inputs are fed to the fuzzy inference mechanism.

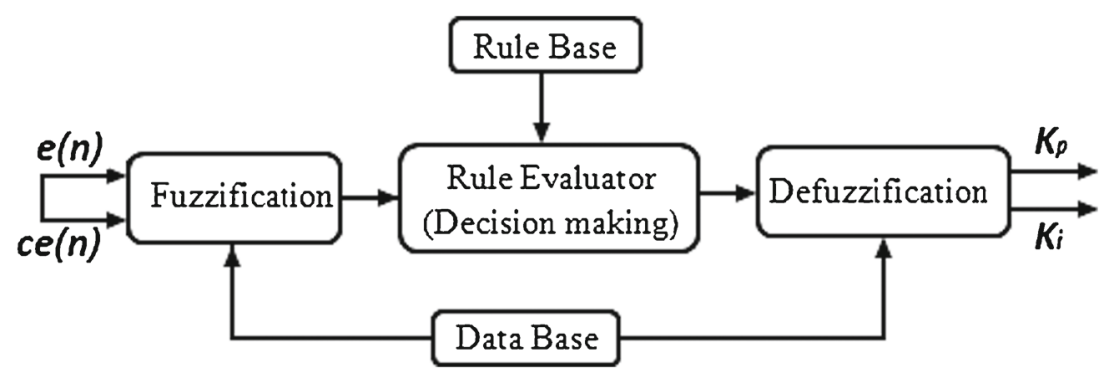

Figure 5. Block diagram of fuzzy logic controller. 


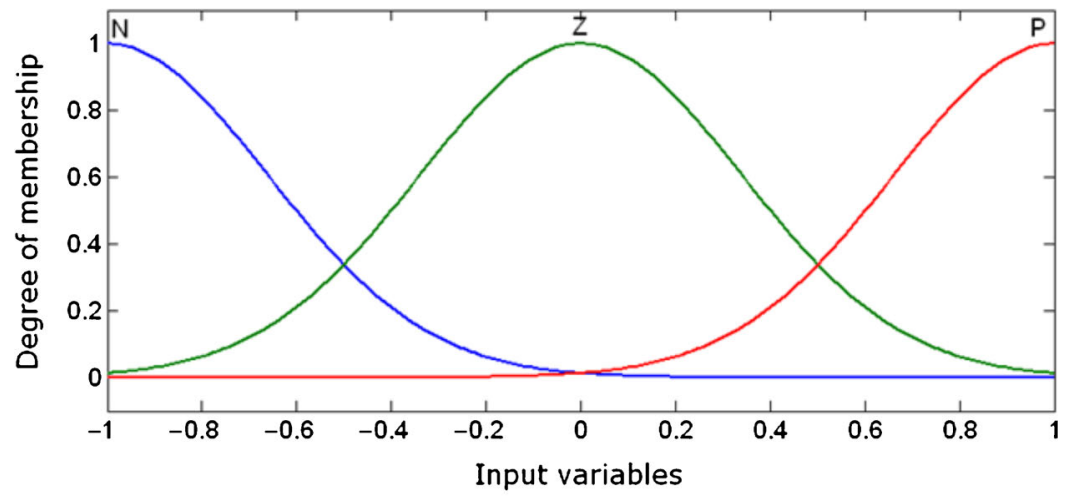

(a)

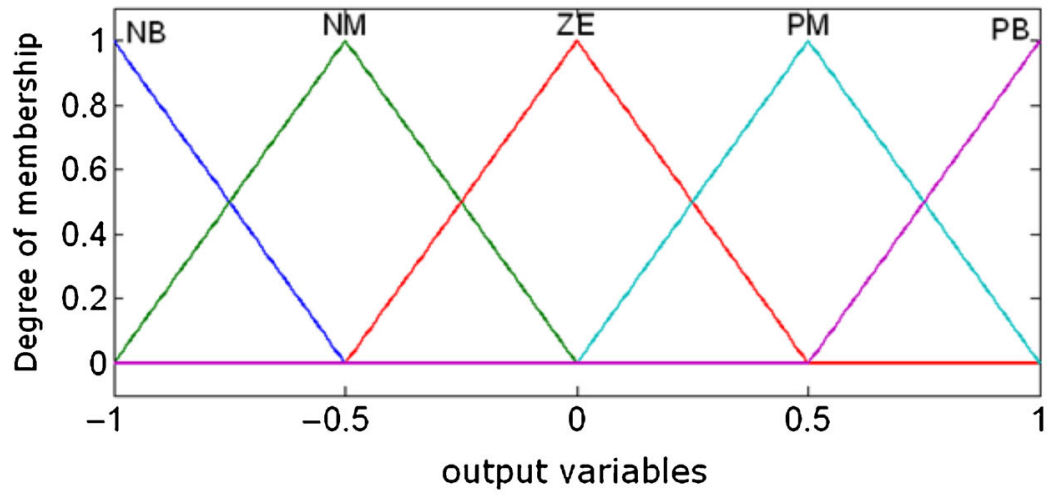

(b)

Figure 6. Membership functions for the input and output variables. (a) Membership functions of the input variable error $e(n)$ and its derivative $c e(n)$, (b) membership functions of the output.

The fuzzy inference mechanism gives the control output based on the given fuzzy rule base. The output of the fuzzy logic controller converting fuzzified output into actual control outputs $\mathrm{K}_{\mathrm{p}}$ and $\mathrm{K}_{\mathrm{i}}$ by using the scaling factors.

This PI controller parameters are obtained from the FLC is used in the proposed PI controller to control the DC link voltage. The output of the PI controller multiplied by $i_{1}^{+}$and is calculated with the reference voltage $\mathrm{V}_{\mathrm{c}}^{*}$, through the above function reference voltage and further corrected

Table 1. Fuzzy rule base table.

\begin{tabular}{llll}
\hline$e$ & de & $\mathrm{K}_{\mathrm{i}}$ & $\mathrm{K}_{\mathrm{p}}$ \\
\hline $\mathrm{N}$ & - & $\mathrm{ZE}$ & $\mathrm{PB}$ \\
$\mathrm{Z}$ & $\mathrm{N}$ & $\mathrm{NM}$ & $\mathrm{PB}$ \\
$\mathrm{Z}$ & $\mathrm{Z}$ & $\mathrm{ZE}$ & $\mathrm{PM}$ \\
$\mathrm{Z}$ & $\mathrm{P}$ & $\mathrm{PM}$ & $\mathrm{NB}$ \\
$\mathrm{P}$ & - & $\mathrm{ZE}$ & $\mathrm{PB}$ \\
\hline
\end{tabular}


to accurate value. The PWM technique is used to control the three-phase VSI to generate the compensation voltage. The gating signals are generated by comparing the reference signal $\left(\mathrm{V}_{\mathrm{C}}^{*}\right)$ with inverter output voltage $\left(\mathrm{V}_{\text {in }}\right)$ using the hysteresis band.

\section{Simulation results}

In this paper, the proposed fuzzy logic-based instantaneous power theory control algorithm for the PV-based SHAPF is evaluated using Matlab/Simulink software under unbalanced and distorted load-current and source-voltage conditions. In the simulation studies, the results are specified before and after the operation of the PV-based SHAPF system.

The SHAPF system parameters are given in table 2. Figure 7 (top to bottom), shows simulation results of the distorted mains voltages before compensation, load voltage after compensation, THD level of load voltage for Phase-A, source current before compensation, source current after compensation, THD level of source current for Phase-A, neutral current before compensation and neutral current after compensation.

The proposed PV-based SHAPF control algorithm has the capability to compensate both the current and voltage harmonics and reactive power, and the neutral current is also reduced. The proposed control scheme has been estimated and verified under unbalanced and nonlinear load conditions. The distorted voltage and current are compensated to make the sinusoidal waveforms at the PCC. The measured THD value of the load voltage in phase-A before compensation was $23.6 \%$ and the source current was $31.3 \%$. The THD value of the load voltage after compensation is about $1.4 \%$ and the source current is around $3.3 \%$, this is fit within the limit specified by IEEE Std. 519-1992.

The simulation results show that the proposed control strategy provides the best compensation for both the current and voltage based distortions in three-phase four-wire distribution systems. In the end, the voltage and current harmonic compensation ability of the proposed PV-based SHAPF control scheme is shown in table 3 as RMS and THD values. From this simulation result analysis the performance of the proposed PV-based SHAPF system has been proved and it is used to design the prototype hardware circuit.

Table 2. The SHAPF system parameters.

\begin{tabular}{lccc}
\hline \multicolumn{2}{c}{ Parameters } & Value \\
\hline Source & Voltage & $\mathrm{V}_{\mathrm{Sabc}}$ & $110 \mathrm{~V}$ \\
& Frequency & $\mathrm{f}$ & $50 \mathrm{~Hz}$ \\
DC link & Voltage & $\mathrm{V}_{\mathrm{dc}}$ & $180 \mathrm{~V}$ \\
\multirow{3}{*}{ Series APF } & Two series capacitor & $\mathrm{C}_{1}, \mathrm{C}_{2}$ & $2200 \mu \mathrm{F}$ \\
& Filter & $\mathrm{L}_{\mathrm{rf}}, \mathrm{C}_{\mathrm{rf}}$ & $12.54 \mathrm{mH}, 75 \mu \mathrm{F}$ \\
& Switching frequency & $\mathrm{f}_{\mathrm{S}}$ & $10 \mathrm{kHz}$ \\
Passive filter & Injection transformer & $\mathrm{T}_{1}, \mathrm{~T}_{2}, \mathrm{~T}_{3}$ & $\mathrm{~N}_{1} / \mathrm{N}_{2}=2,5.4 \mathrm{kVA}$ \\
& LC value & $\mathrm{L}_{5}, \mathrm{C}_{5}$ & $12.5 \mathrm{mH}, 33 \mu \mathrm{F}$ \\
Non-linear load & LC value & $\mathrm{L}_{7}, \mathrm{C}_{7}$ & $6.8 \mathrm{mH}, 33 \mu \mathrm{F}$ \\
& $3 \Phi$ thyristor rectifier & $\mathrm{L}_{\mathrm{L}}, \mathrm{L}_{\mathrm{Dc}}, \mathrm{R}_{\mathrm{Dc}}$ & $3 \mathrm{mH}, 5.7 \mathrm{mH}, 12 \Omega$ \\
& RL load & $\mathrm{R}_{\mathrm{L}}, \mathrm{L}_{\mathrm{L}}$ & $7 \Omega, 75 \mathrm{mH}$ \\
\hline
\end{tabular}




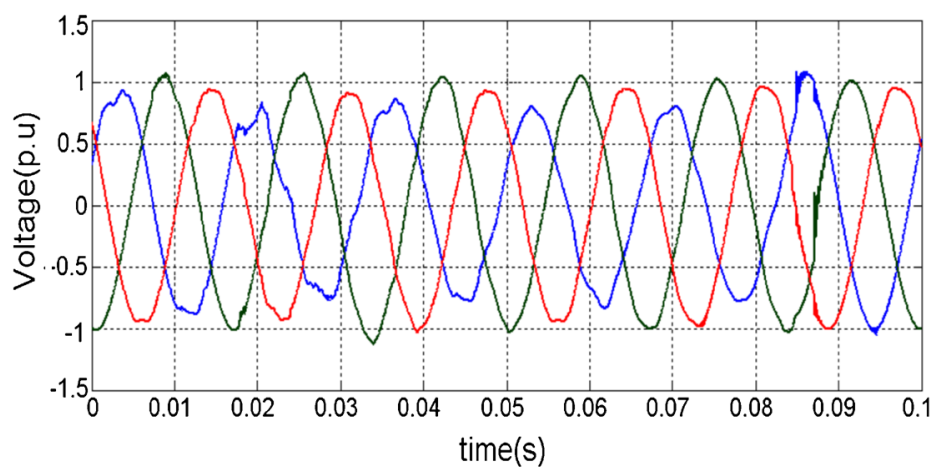

(a)

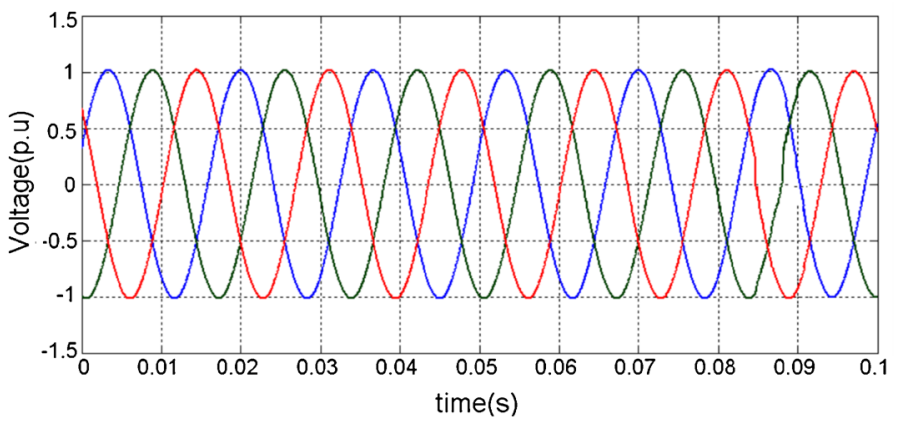

(b)

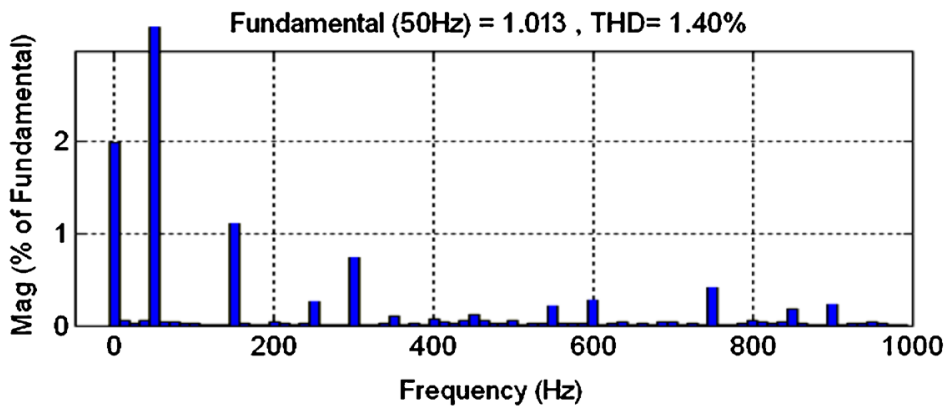

(c)

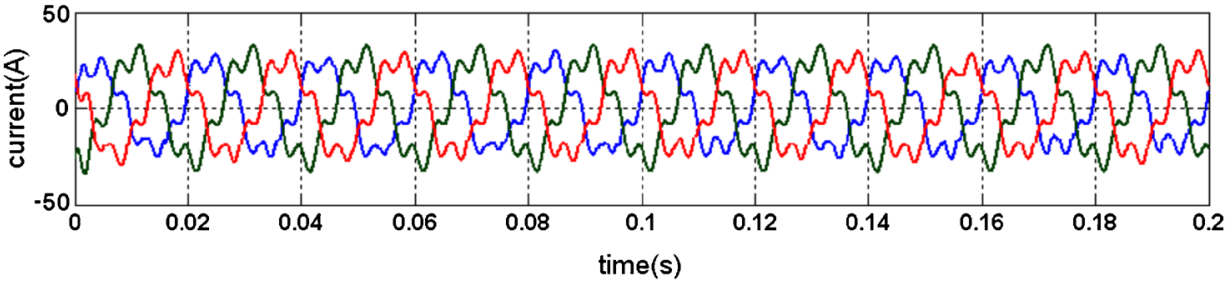

(d)

Figure 7. Simulation results for operational performance of the proposed system. (a) Distorted mains voltages before compensation. (b) Load voltage after compensation. (c) THD level of load voltage to PhaseA. (d) Source current before compensation. (e) Source current after compensation. (f) THD level of source current for Phase-A. (g) Neutral current before compensation and (h) neutral current after compensation. 


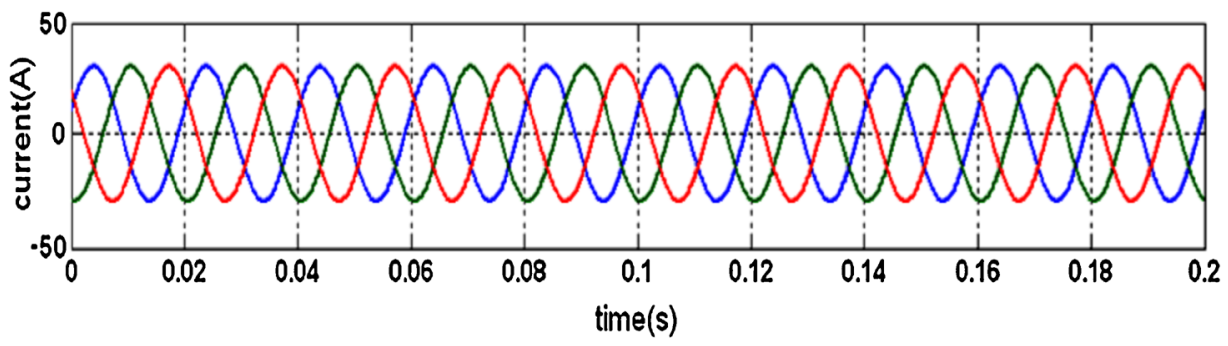

(e)

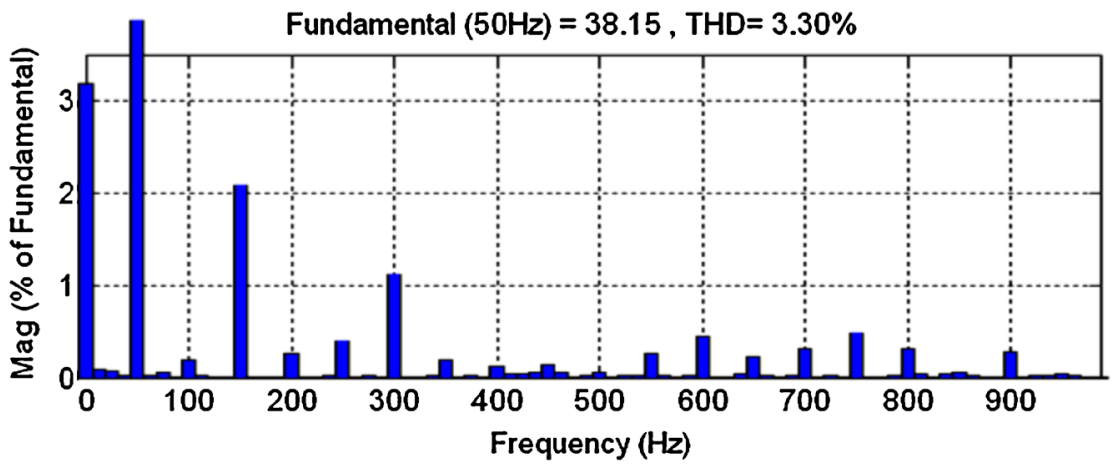

(f)

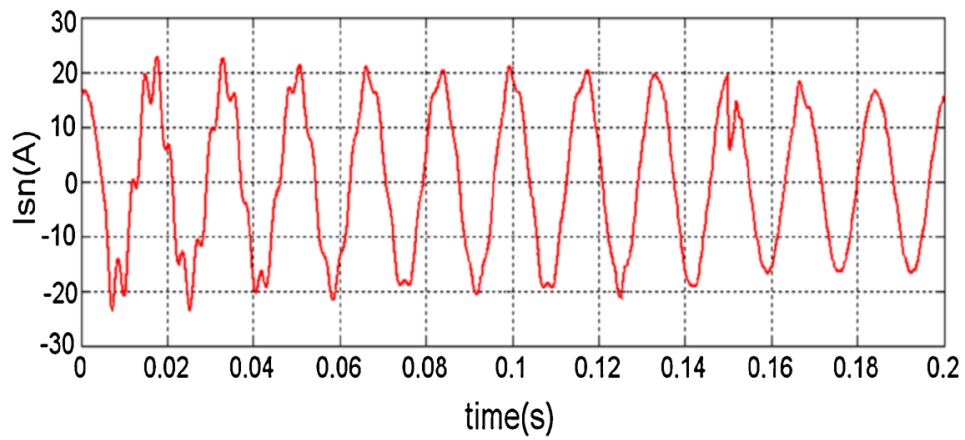

(g)

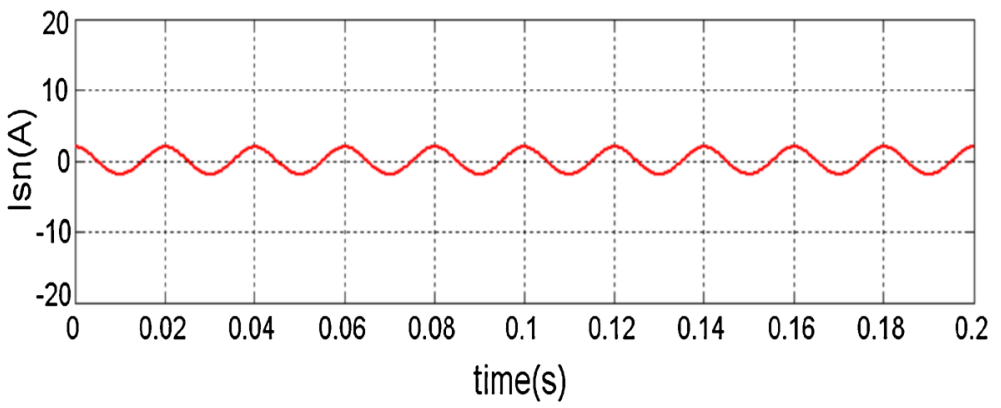

(h)

Figure 7. (continued) 


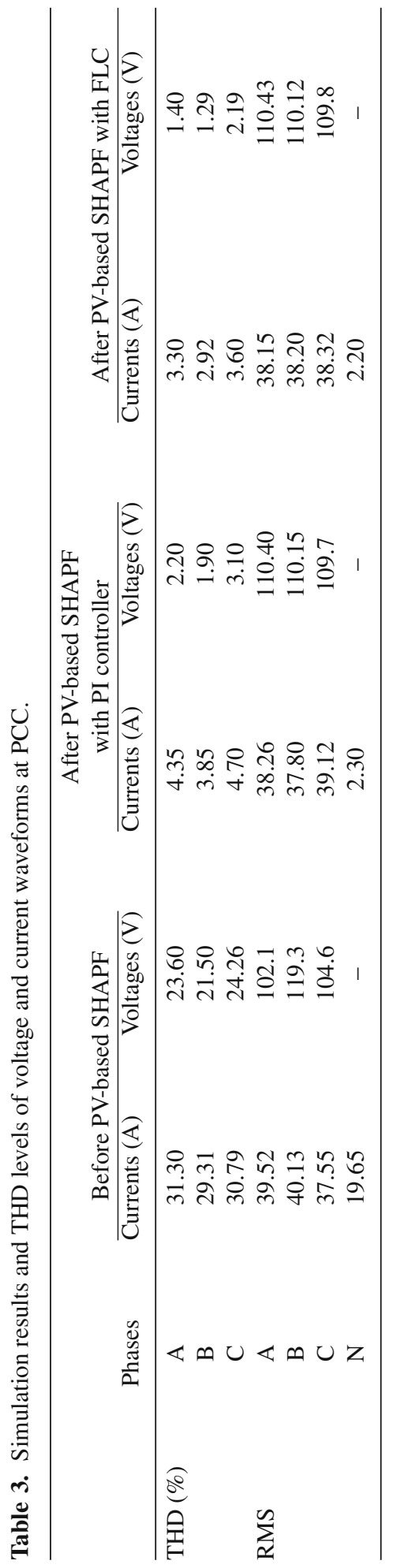




\section{Experimental results}

The experimental prototype in the three-phase four-wire PV based SHAPF system consists of a voltage source inverter (series APF) and shunt passive filter. The voltage source inverter is connected with DC bus split-capacitor and the dsPIC30F4011 device for controlling the SHAPF system. The dsPIC30F4011 device contains extensive Digital Signal Processor (DSP) functionality within a high performance 16-bit microcontroller (MCU) architecture with $48 \mathrm{~kb}$ Internal Flash program memory. The Microcontroller includes a 9-channel 10-bit A/D convertor with fast response time together with support for SPI and $\mathrm{I}^{2} \mathrm{C}$ communication. This Controller board also includes a large number of general I/O points with standard header for easy connections to connect the external devices.

The experimental prototype scheme is shown in figure 8, the series APF is connected in series with the line using series coupling transformer. The DC links of series APFs are connected to two common series $2200 \mu \mathrm{F}$ DC capacitors under $180 \mathrm{~V}$ DC in split capacitor topology. PV connected DC-DC boost converter is connected to the DC-link, in which DC voltage is stored using the DC link capacitor. A three-phase diode bridge rectifier with RL loads are used as nonlinear loads. All of the prototype circuit parameters and experimental environment are set-up nearly the same as the simulation conditions. The experimental results are in close agreement with the simulation results, by which it satisfies the control objectives of the proposed system effectively.

Figure 9 (top to bottom), shows experimental results of the distorted mains voltages before compensation injected voltage of series active filter, load voltage after compensation, THD level

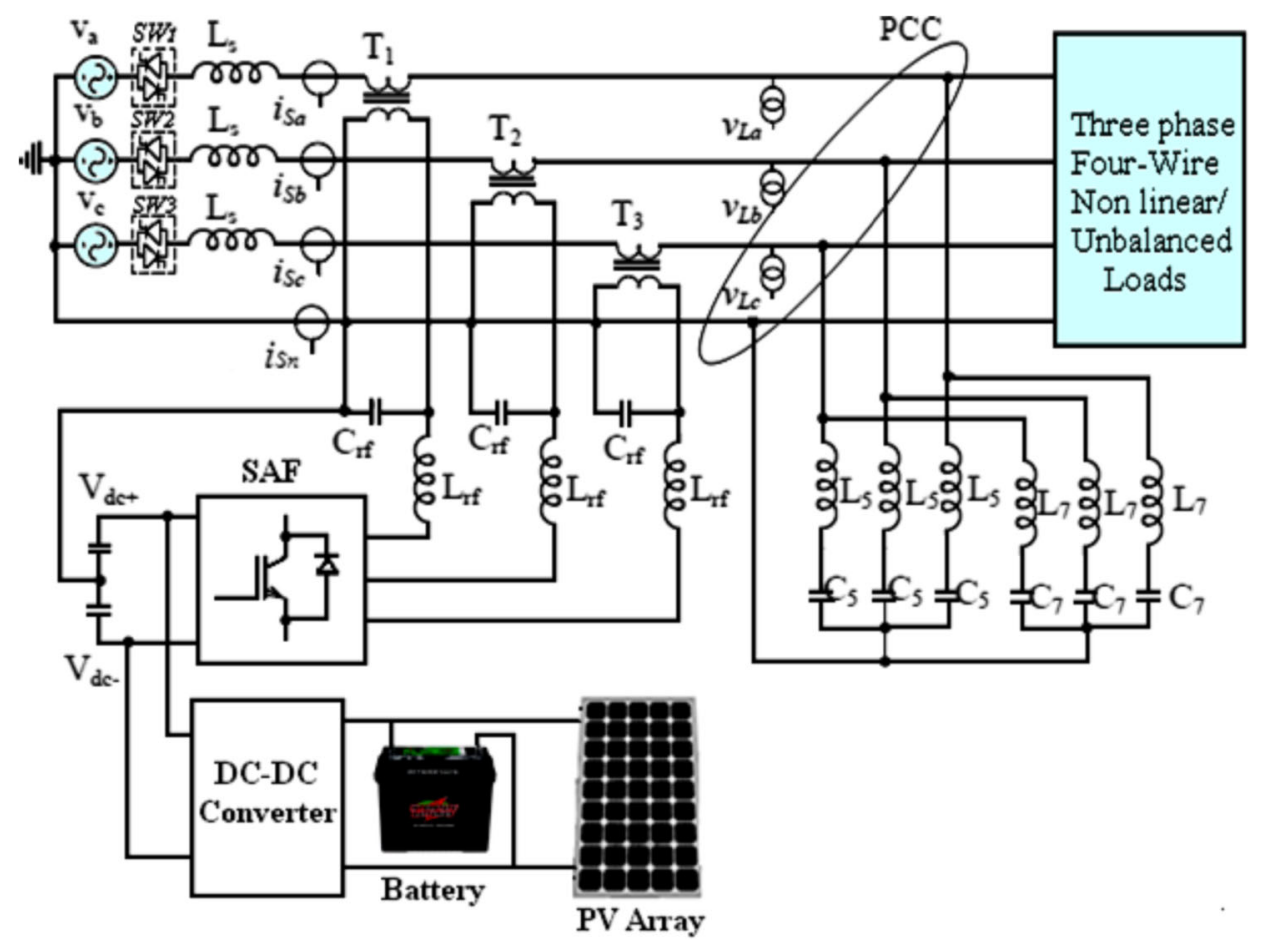

Figure 8. PV-based series active filter with shunt passive filter topology. 


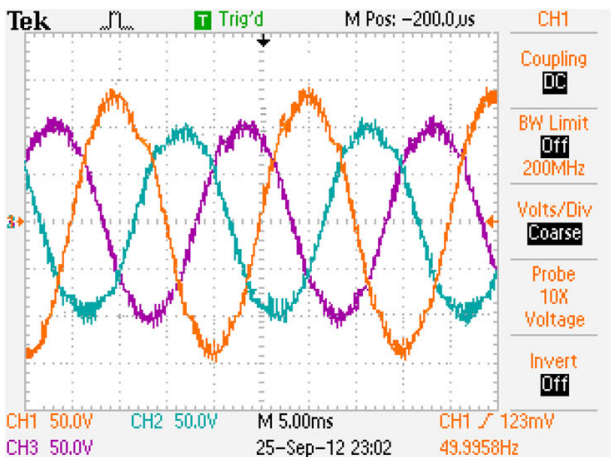

(a)

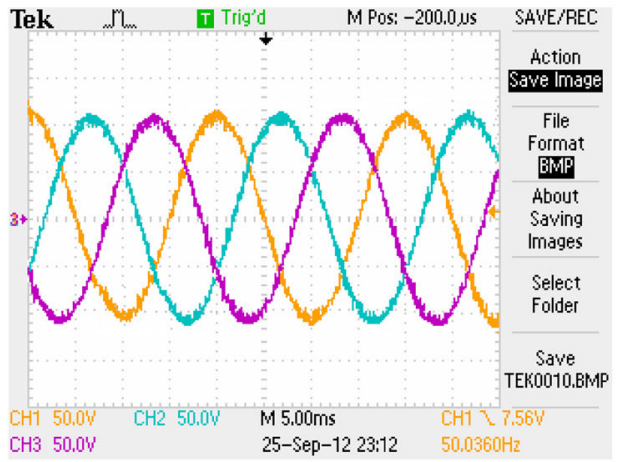

(c)

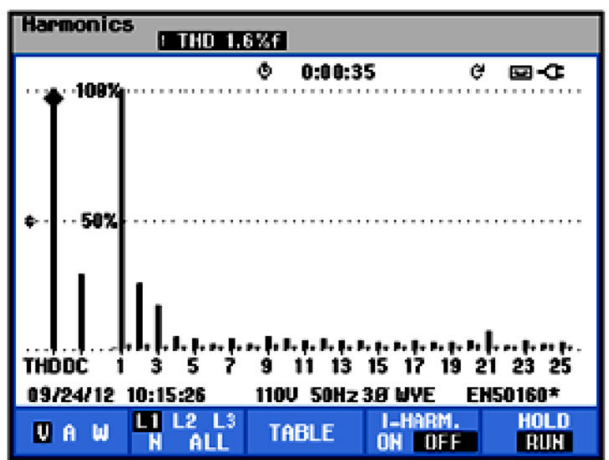

(e)

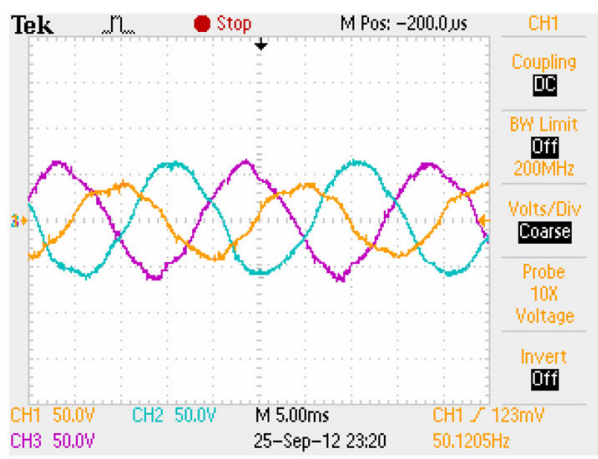

(b)

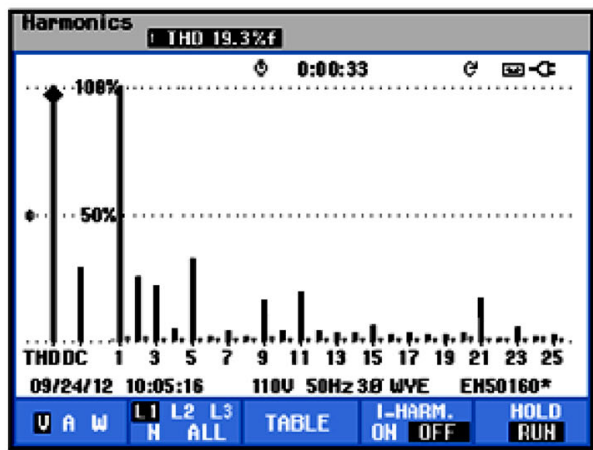

(d)

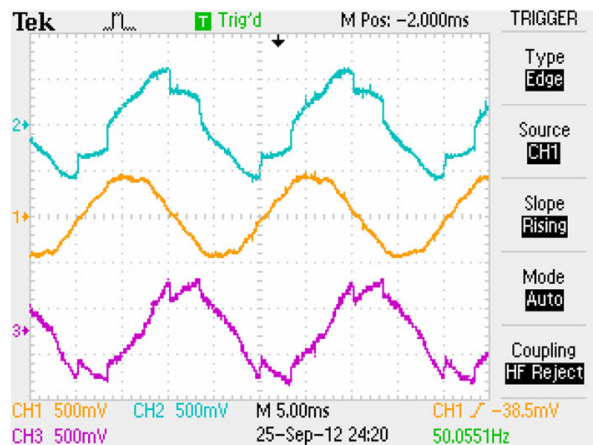

(f)

Figure 9. Experimental results of the proposed system. (a) Distorted mains voltages before compensation. (b) Injected voltage of series active filter. (c) Load voltage after compensation. (d) THD level of load voltage before compensation for Phase-A. (e) THD level of load voltage after compensation for Phase-A. (f) Supply, load and injected current of Phase-A. (g) Source voltage and neutral current before compensation. (h) DC link voltage and neutral current after compensation. (i) THD level of source current before compensation for Phase-A and (j) THD level of source current after compensation for Phase-A.

of load voltage before compensation for Phase-A, THD level of load voltage after compensation for Phase-A, supply, load and injected current of phase-A, source voltage and neutral current 


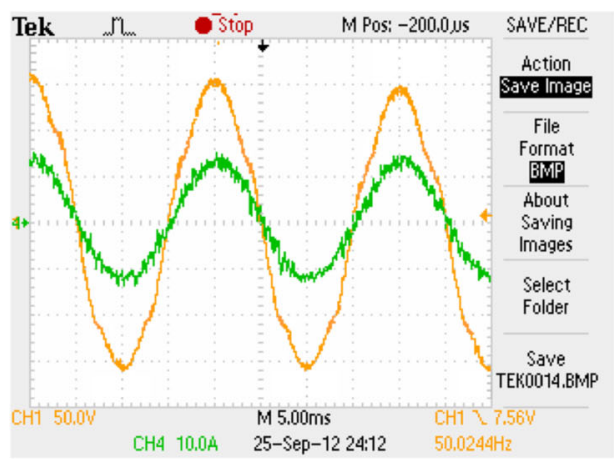

(g)

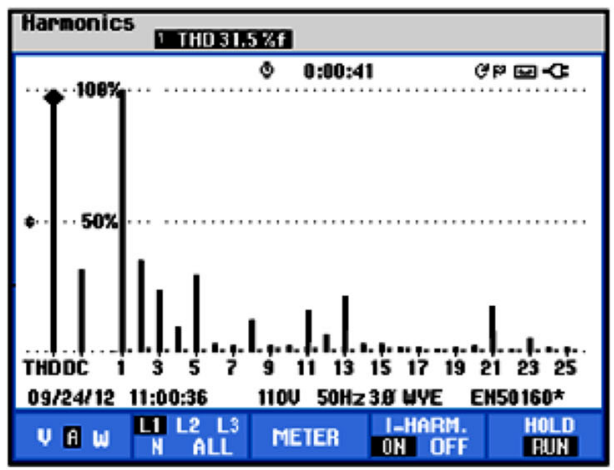

(i)

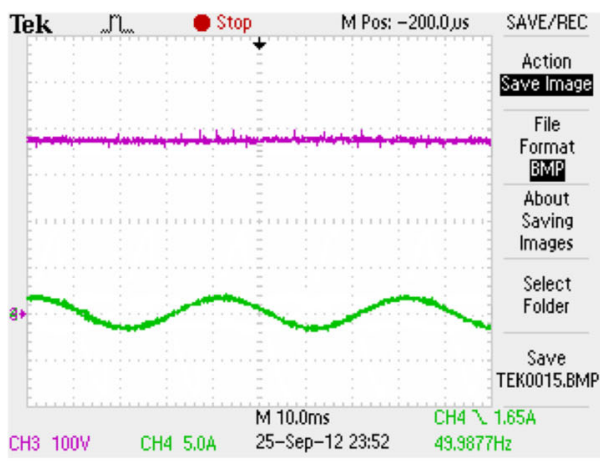

(h)

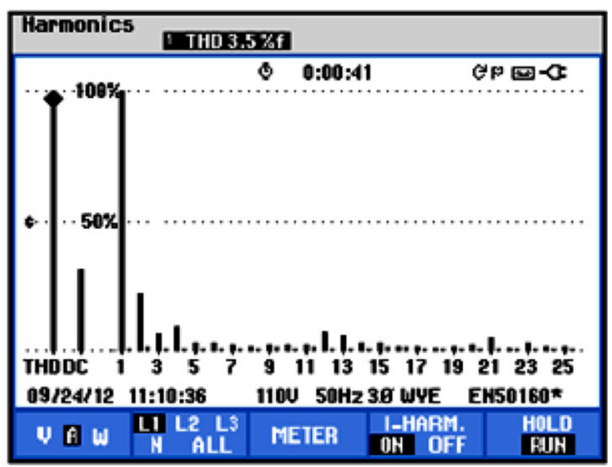

(j)

Figure 9. (continued)

before compensation, DC link voltage and neutral current after compensation, THD level of source current before compensation for Phase-A and THD level of source current after compensation for Phase-A. The following results of the experimental prototype voltage and current based compensation performance and power quality improvement evaluated through the digital oscilloscope and power quality analyzer.

The compensation results of the experimental set-up are summarized in table 4 in terms of THD values of voltage and current waveforms. The experimental results show the feasibility of prototype hardware implementation of the proposed system and this result almost coincides with the simulation results.

Table 4. Experimental results in terms of THD levels of voltage and current waveforms at PCC.

\begin{tabular}{ccccccc}
\hline & & \multicolumn{2}{c}{ Before PV-based SHAPF } & & \multicolumn{2}{c}{ After PV-based SHAPF } \\
& Phases & Currents (A) & Voltages (V) & & Currents (A) & Voltages (V) \\
\hline THD (\%) & A & 31.50 & 19.30 & & 3.50 & 1.60 \\
& B & 34.90 & 23.20 & & 4.10 & 1.90 \\
& C & 29.70 & 25.60 & 3.40 & 2.70 \\
\hline
\end{tabular}




\section{Conclusions}

This paper explicates a new control algorithm based on the dual formulation of the vectorial theory of electrical power theorem with FLC used in the PV-based SHAPF. The proposed system is mainly for compensating the reactive power along with voltage and current harmonics under nonlinear and unbalanced conditions. In this proposed control algorithm, FLC was used to adapt PI controller parameters $\mathrm{K}_{\mathrm{p}}$ and $\mathrm{K}_{\mathrm{i}}$ to control DC link voltage. The simulation results show that when under unbalanced and nonlinear load conditions, the proposed control scheme eliminates the impact of distortion and unbalance of the load current on the power system. The series active filter controlled as a harmonic isolator in unbalanced and distorted load conditions, and forcing the load current harmonics to circulate mainly through the shunt passive filter rather than the three-phase distribution system. The shunt passive filter compensates reactive power and current harmonics and provides three-phase balanced and rated currents for the supply mains. Experimental results are obtained from a laboratory prototype model to verify the viability and effectiveness of the proposed control algorithm. This proposed system configuration thus eliminates the need for additional conventional energy source required for the series active filter.

\section{References}

Akagi H 1996 New trends in active filters for power conditioning. IEEE Trans. Ind. Appl. 32(6): 1312-1322

Akagi H, Watanabe E H and Aredes M 2007 Instantaneous Power Theory and Applications to Power Conditioning IEEE Press: Wiley

Altas H and Sharaf A M 2007 A Photovoltaic Array Simulation Model for MATLAB Simulink GUI Environment. Proc. ICCEP '07:341-345

Asiminoaei L, Blaabjerg F and Hansen S 2007 Detection is key-harmonic detection methods for active power filter applications. IEEE Ind. Appl. Mag. 13(4): 22-33

Bhattacharya S, Divan D M and Banerjee B B 1993 Control and Reduction of Terminal Voltage Total Harmonic Distortion (THD) in a Hybrid Series Active and Parallel Passive Filter System. IEEE Power Electron. Specl. Conference 779-786

Bose B K 1999 Expert Systems, Fuzzy Logic and Neural Network Applications in Power Electronics and Motion Control. Piscataway, NJ: IEEE Press

Choi S and Jang M 2004 A reduced-rating hybrid filter to suppress neutral current harmonics in three-phase four-wire systems. IEEE Trans. Ind. Electron. 51(4): 927-930

Das J C 2004 Passive filters - potentialities and limitations. IEEE Trans. Ind. Appl. 40(1): 232-241

Dugan R C, McGranaghan M F, Santoso S and Beaty H W 2002 Electr. Power Syst. Q. New York: Mc Graw Hill

Fujita H and Akagi H 2007 Voltage-regulation performance of a shunt active filter intended for installation on a power distribution systems. IEEE Trans. Power Electron. 22(3): 1046-1053

Hamadi A, Rahmani S and AI-Haddad K 2007 A Novel Hybrid Series Active Filter for Power Quality Compensation. IEEE Power Electron. Specl. Conference 1099-1104

Herrera R S and Salmerón P 2007 Instantaneous reactive power theory: a comparative evaluation of different formulations. IEEE Trans. Power Deliv. 22(1): 595-604

Jain S K, Agrawal P and Gupta H O 2002 Fuzzy logic controlled shunt active power filter for power quality improvement. Proc. Inst. Elect. Eng. Electr. Power Appl. 149(5): 317-328

Jiang W, Zhou Y-F and Chen J-N 2009 Modeling and Simulation of Boost Converter in CCM and DCM. IEEE Conference PEITS 288-291

Jindal A K, Ghosh A and Joshi A 2005 The protection of sensitive loads from interharmonic currents using shunt series active filters. Elect. Power Syst. Res. 73(2): 187-196 
Kwon J-M, Nam K-H and Kwon B-H 2006 Photovoltaic Power Conditioning System With Line Connection. IEEE Trans. Ind. Electron. 53(4): 1048-1054

Mazouz N and Midoun A 2011 Control of a DC/DC converter by fuzzy controller for a solar pumping system. Int. J Electr Power Energy Syst. 33(10): 1623-1630

Ojo O and Kshirsagar P M 2004 Concise modulation strategies for four-leg voltage source inverters. IEEE Trans. Power Electron. 19(1): 46-53

Peng F Z and Lai J S 1996 Generalized instantaneous reactive power theory for three-phase power systems. IEEE Trans. Instrum. Meas. 45(1): 293-297

Rahim N A, Islam Z and Raihan S R S 2010 FPGA-based PWM control of hybrid single-phase active power filter for harmonic compensation. J. Sci. Ind. Res. 69(01): 55-61

Rashid M H 1993 Power Electronics: Circuits, Devices and Applications. Englewood Cliffs: Prentice-Hall: Inc.

Rivas D, Morán L, Dixon J and Espinoza J R 2003 Improving passive filter compensation performance with active techniques. IEEE Trans. Ind. Electron. 50(1): 161-170

Routimo M, Salo M and Tuusa H 2007 Comparison of voltage-source and current-source shunt active power filters. IEEE Trans. Power Electron 22(2): 636-643

Salmerón P and Litrán S P 2010 A Control strategy for hybrid power filter to compensate four-wire threephase systems. IEEE Trans. Power Electron. 25(7): 1923-1931

Saribulut L and Tumay M 2011 A Novel Reference Signal Generation Method for Power-Quality Improvement of Unified Power-Quality Conditioner. IEEE Trans. Power Deliv. 26(4): 2205-2214

Singh B, Al-Haddad K and Chandra A 1999 A review of active filters for power quality improvement. IEEE Trans. Ind. Electron. 46(5): 960-971

Singh B N, Rastgoufard P, Singh B, Chandra A and Al- Haddad K 2004 Design, Simulation and Implementation of Three Pole/Four Pole Topologies for Active Filters. IEE Electric. Power Appl. 151(4): 467-476

Vodyakho O and Mi C C 2009 Three-Level Inverter-Based Shunt Active Power Filter in Three-Phase ThreeWire and Four-Wire Systems. IEEE Trans. Power Electron. 24(5): 1350-1363 